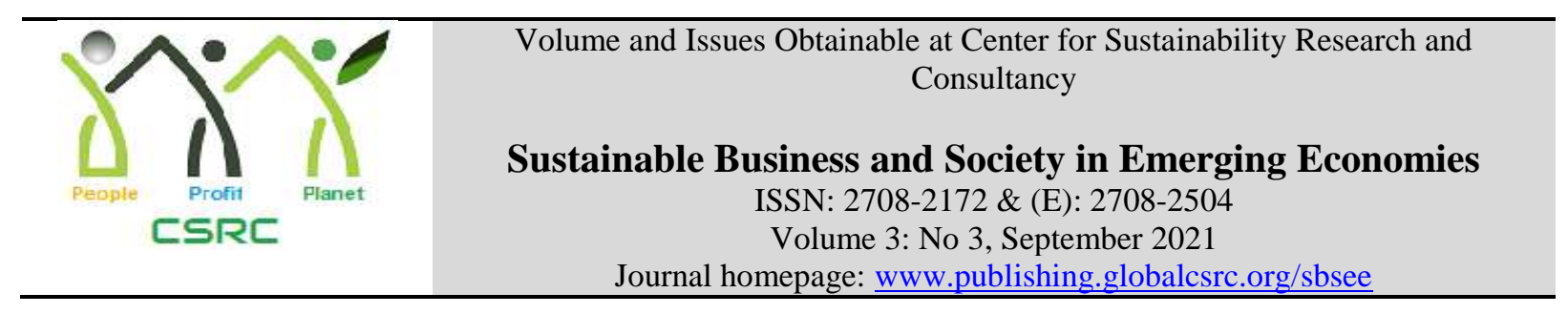

\title{
Evaluating the Impact of Behavioral Factors on Purchase Intention of Green Products in Pakistan
}

Muhammad Ikram, M.Phil Scholar, Department of Commerce, The Islamia University of Bahawalpur, Pakistan

*Ayesha Shoukat, Assistant Professor at Department of Commerce, The Islamia University of Bahawalpur, Pakistan

Corresponding Author: ayesha.shoukat@iub.edu.pk

\begin{tabular}{l}
\hline ARTICLE DETAILS \\
\hline History \\
Revised format: Aug 2021 \\
Available Online: Sep 2021
\end{tabular}

\section{Keywords}

Theory of planned behavior, Green Purchase Intention, Attitude toward Green Product, Environmental concern, Subjective Norm, Willingness to pay more

JEL Classification $M 1, M 2$

\begin{abstract}
Purpose: Today, global warming is one of the most pressing issues facing the world, and it is primarily caused by greenhouse gases. Thus, the development of green products is one of the industrial endeavors to address this dilemma by permitting at least partial proportionate decrease in globalgas-emissions. Determinants of customer purchasing intention for green products are examined in this study.

Design/Methodology/Approach: For conducting this research, the data is gathered from 304 respondents. SPSS is used for descriptive analysis and inferential analysis using the software Smart PLS 3. The provided hypothesis was analyzed in two-step approach using partial least squares structural equation modeling (Smart-PLS 3).

Findings: The findings revealed that ATGP and SN do not significantly influence green purchase intention but have an indirect impact on it. WTP has a significant mediation between ATGP, SN and GPI, while EC are seen to predict directly and indirectly GPI.

Implications/Originality/Value: To explain the effect of behavioral factors on green purchasing intention, this study uses willingness to pay as a mediator to add environmental concern as a predictor to the standard TPB behavioral model. The novelty of the study is evaluating the mediating impact of willingness to pay more.
\end{abstract}

(C) 2021 The authors, under a Creative Commons AttributionNon Commercial 4.0 Recommended citation: Ikram, M., and Ayesha, S. (2022). Evaluating the Impact of Business and Society in Emerging Economies, 3(3), 421-437

\section{Introduction}

There has been increasing concern about global warming, climate change, depletion of natural resources and degradation of renewable land, erosion, and ozone layer loss that has made more consumers aware of their environmental problems. We have to think and speak about sustainable protection and practice in the current scenario. Two of the most emergent issues are global warming and climate change faced by the entire world. The imminent and devastating effects of climate change on human life, economic growth and prosperity are 
perceived to be one of the huge challenges for mankind (Pérez-Suárez \& López-Menéndez, 2015).

Global warming is defined as, "Incidental human acts like greenhouse gas emissions cause the Earth's average surface temperature to rise by burning fossil fuels through deforestation. The warming of the Earth over the last 50 years has been demonstrated mainly by anthropogenic activities (Mackay, 2008).

Global warming has been noticed in recent decades. A recent example of climate change's influence on natural and human systems Temperature change, rainfall pattern, $\mathrm{CO} 2$ level in the atmosphere, and the frequency and intensity of extreme weather events might all have a substantial influence on agriculture. Global warming is expected to reduce agricultural productivity by 9 to $21 \%$ in developed countries (Cline, 2007). Bakhtyar (2019) also mentioned in his study that greenhouse gas (GHG) emissions will significantly increase and natural resources will be degraded. Pakistan has a complex air pollution mix. Mobile vehicles include high-speed vehicles and two- or three-wheelers. Stationary sources include thermal power plants and industrial operations (TheWorldBank, 2019).

Pakistan has a very severe impact on health, worldwide competitiveness and economic productivity, and its natural resources because of Pakistan's environmental deterioration (TheWorldBank, 2019). However, the degradation of air and water and natural resources still imposes heavy costs on the people of Pakistan and economy through their influence on health and productivity (TheWorldBank, 2019).

Consumers contribute directly or indirectly to the worsening of the environment through product choice and waste disposal decisions (Gooch \& behavior, 1995; Stern et al., 1995). $30-40 \%$ of environmental degradation has been estimated to be caused by household activities (Grunert, 1993), researchers and environmental activists are generally convinced of the numerous contributions made by buying environmental products, recycling product packs, or disposing of non-biodegradable waste to enhance environmental quality. There has been increased public concern about environmental concerns. Many customers are aware that their purchasing behavior can harm the environment and begin searching for and purchasing ecologically friendly products and even paying a premium for them (Kahn \& Management, 2007; Laroche et al., 2001; J.-S. Lee et al., 2010). This environmental concern has evolved into environmentally friendly and sustainable buying practices (Do Paco et al., 2009). This has made green consumption a significant force for environmental protection and earth conservation (Y. Kim \& Choi, 2005).

How many of those people realize that daily activities, such as driving a car or buying new goods, lead to expanding environmental issues directly or indirectly? Individuals' contributions are not critical, but they inspire businesses and industries to increase production and make better use of the planet's resources (Charter, 1992). Therefore, without customer awareness, achieving sustainability is difficult. The world's people must be able to take environmental care and responsibility. Customers are becoming more aware that environmental degradation is serious. It is easier to acquire and spread knowledge because of the digital world. It leads to an increase in environmental awareness and changes in environmental attitudes and beliefs (Kaufmann et al., 2012; Y. Kim \& Choi, 2005). Consumers are aware that their purchase choices have a major environmental impact (Vazifehdoust et al., 2013). Customers are maturing in their understanding of their preferences and attitudes about these issues.

Consumers have taken on sustainable consumption through environmentalism in the past two decades (Han et al., 2009; Kalafatis et al., 1999). As people become conscious of environmental concerns associated with their purchases, they are trying to buy eco-friendly products (W. E. Kilbourne et al., 2009) for the sake of future generations. The understanding 
and interest in sustainable consumption should have an impact on consumer buying decisions (de Moura et al., 2012).

In response to the above discussion, PSO mentioned in its annual report that the health and safety of internal and external stakeholders are of utmost importance and a vital part of the key business goal. The firm is committed to conducting business in a sustainable manner that has a minimal environmental effect. PSO's emphasis on environmental conservation can be supported by its environmentally-friendly fuel initiatives 97 euro 5 and euro 5 hi-octane Altron Premium, as well as the launch of charging units for electric vehicles under the Electro brand. PSO is the first oil marketing company to improve Pakistan's Euro 2 to Euro 5 gasoline standards (PSO, 2020)

One of the issues in research is that Pakistani customers' attitudes about green products are ambiguous. People are becoming more aware of the need of environmental preservation and are seeking out green products. Green purchasing are still in their infancy in many developing nations, including Pakistan. There is no study on green consumption in Pakistan, utilizing individual behavioral factors and desire to pay extra for eco-friendly products. Researchers overlooked the influence of willingness to pay more as a mediator. So research on the willingness to pay more mediating influence is required.

It is worthwhile to conduct a detailed examination of these arguments. Therefore, this is a novel domain which has not been studied before, along with all these variables present in this study, including attitude toward green products, environmental concern, subjective norms and willingness to pay more, green purchase intention. Specifically, in the present study, behavioral factors such as Attitude towards green product, subjective norms, and environmental concern will be discussed in relation to the Green purchase intention. Second, we will examine the mediating impact of willingness to pay more between behavioral factors and green purchase intention.

\section{Theoretical framework}

From the introduction of this theory till now, the planned behavior theory becomes the most cited and used very often by the measures of its objectives, also prestigious models to predict the behaviors of individuals (Ajzen, 2011). In line with planned behavior theory, intention is a crucial determinant for behavior (Ajzen, 1991). In point of fact, planned behavior theory in several researches is effectively utilized for scrutiny a link in between intentions and actual behavior (Ferdous, 2010). Planned behavior theory used for understanding the green consumption behavior (Albayrak, Aksoy,\& Caber,2013). The study's framework is completely supported by planed behavior theory (I. Ajzen, 1985). Customer's willingness and internal incentive to purchase environmentally friendly items may be termed as "consumer intention" (Dagher \& Itani, 2014). Figure 1 depicts the theoretical framework for this study's assessment of Pakistani customers' purchase intentions for green products, on the basis of TPB's theoretical framework. Moreover, numerous research have proven TPB's validity as a model to predict customer behavior towards environment friendly products in Asia, such as organic foods and veggies (Zagata, 2012; Zhao et al., 2014), energy-efficient products (Ha \& Janda, 2012), environment friendly packaging (Prakash \& Pathak, 2017) and general ecofriendly products (Lai \& Cheng, 2016; Yadav \& Pathak, 2016). 


\section{Relationship between behavioral factors (ATGP, EC, SN) and willingness to pay more}

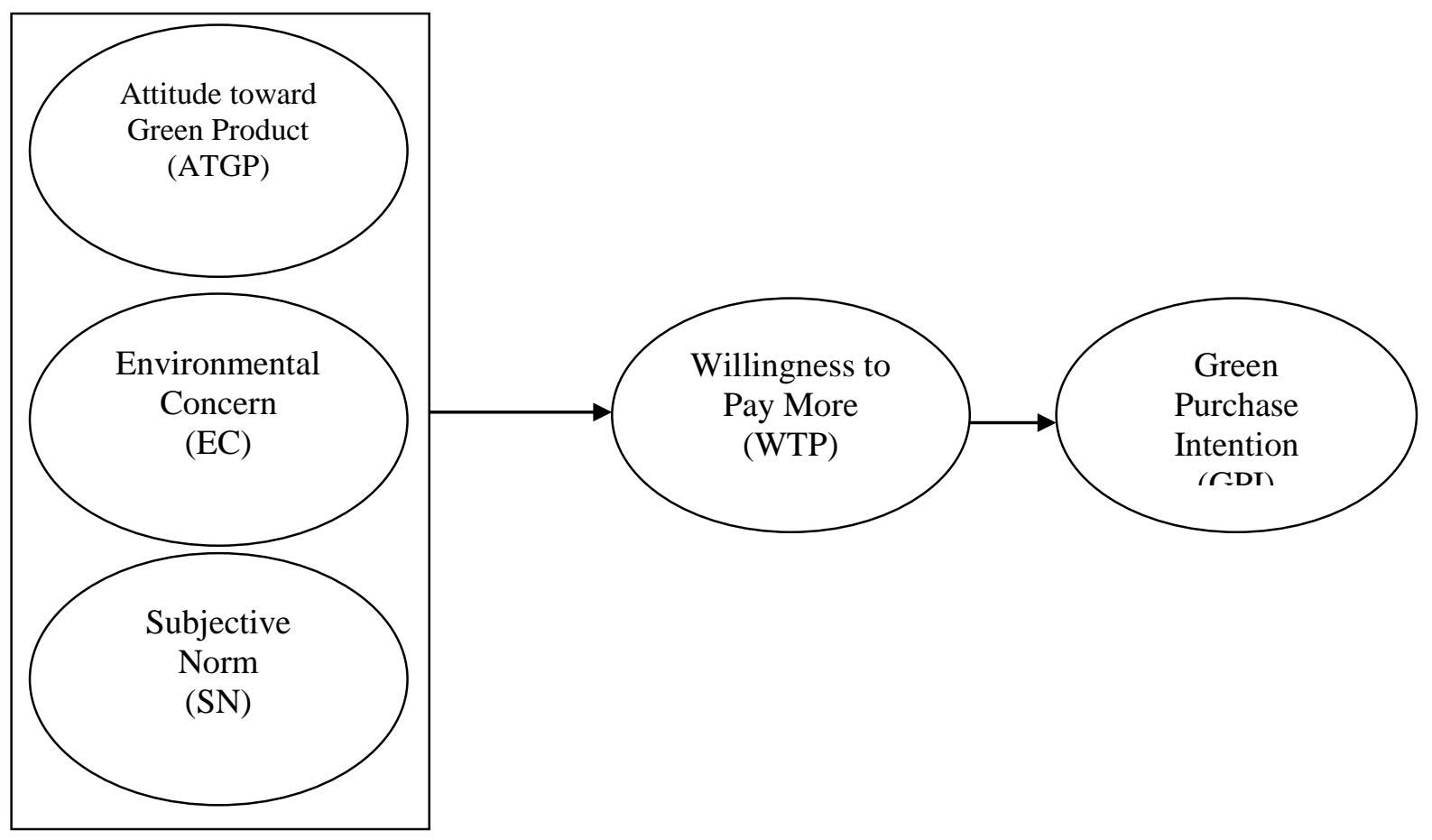

Figure1. Conceptual Framework

Attitude refers to an individual's perception of a particular behavior as favorable or unfavorable (I. Ajzen, 1985). The attitude toward green products is a clear indicator of a customer's readiness to pay a premium for them. Green or eco-friendly items have been demonstrated to be attractive, even among consumers willing to pay a premium for them (Coddington, 1990; Laroche et al., 2001; Myburgh-Louw \& O'Shaughnessy, 1993). Economic value is determined by measuring the maximum amount of willingness for a person to sacrifice to obtain goods and services (Hartono \& Harahap, 2007). This notion is formally called readiness to pay for goods and services produced by someone. Payments are utilized to determine the more people who are prepared to pay. This research examines, willingness to pay more is a variable that measures the willingness of a person to pay the price difference between non-green and green products. As previously stated, environmental awareness has significantly increased. Many people who have a favorable attitude toward green products consider themselves to be environmentalists and expresses its desire to make extra efforts to buy items or services from environmentally friendly organizations (Donaton \& Fitch, 1992; Hume et al., 1989).

The amount of awareness of environmental problems and their efforts at resolving them is known as environmental concerns (EC) (Tan et al., 2017). EC is a widely studied environmental variable and it has been discussed by most of the researchers as far as studies on green products are concerned. It is commonly referred regarded as a person's knowledge and readiness to become part of the solution to the environmental problem (Y. Kim \& Choi, 2005). Environmental concerns are a multifaceted structure that refers to how concerned people are concerned and even prepared to pay a green product premium (Dunlap \& Jones, 2002). Numerous research evaluated consumer concern and willingness to pay for sustainable products (Van Doorn \& Verhoef, 2011).

Subjective norms are defined as societal pressure to do or refrain from performing a particular action (I. J. O. b. Ajzen \& processes, 1991). SN is perceived to have an effect on the WTP for RE through the influence of coworkers, friends, and family members. For instance, Lopes et al. (2019) established a positive connection between SN and energy saving attitudes of households. Based on these findings, for the current study we propose that: 
H1. Attitude toward green product is positively related to willingness to pay more.

H2. Environmental concerns are positively related to the willingness to pay more.

H3. Subjective norms positively influence willingness to pay more.

\section{Relationship between behavioral factors (ATGP, EC, SN) and Green Purchase Intention}

Attitude is a psychology term that refers to a person's like or disliking of something (Eagly \& Chaiken, 2007). The notion of planned behavior is more positive that a specific behavior is more likely to happen (I. J. O. b. Ajzen \& processes, 1991). In previous empirical investigations, the claim is that the attitude and purchasing intentions have favorable relationships (Bredahl, 2001; M.-F. J. F. Q. Chen \& preference, 2007; Michaelidou \& Hassan, 2010; Sheppard et al., 1988; Tang \& Medhekar, 2008). According to Laskova (2007), people with strong environment concerns are more eco-friendly than people who feel that they are more environmentally friendly than those who do not engage in ecoenvironmental activities. The examination of this argument is also justified Y. Kim and Choi (2005), in cases of environmental concerns which affect customer buying green products directly and positively. Besides Mostafa (2009) it emphasized the relevance for the consumer's green purchase behavior, together with other characteristics. Additionally, he stated that it is feasible to discriminate between green and conventional customers based on environmental concerns. There are several authors who observed that EC and environmentally friendly behavior are correlated (Kinnear et al., 1974; Roberts \& Bacon, 1997; Straughan \& Roberts, 1999).

The perceived/social compulsion to conduct specific behavior is referred to as a "subjective norm" (I. Ajzen, 1991; Fishbein \& Ajzen, 1977). Subjective norm as perceived social force can be presented. If the individual acts under social pressure the subjective norms provide an estimate of the appropriate level of behavior (Jager, 2000). Social norms may also influence people's purchasing decisions (I. Ajzen, 1991). Subjective standards have a major impact on consumers when purchases for specific goods and services, the effects are stronger than purchasing behavior (Ali et al., 2019; Bashir et al., 2019; T. B. Chen \& Chai, 2010; Jaiswal \& Kant, 2018; Lai \& Cheng, 2016; K. Lee, 2008; Qi \& Ploeger, 2019; Yadav \& Pathak, 2016). If someone believes that other people consider green products are good, consumers are likely more willing to purchase these products (H. Y. Kim \& Chung, 2011). Based on these findings, for the current study we propose that:

H4: Attitude toward green products positively influences green purchase intention.

H5: Environmental concern positively influences green purchase intentions.

H6: Subjective norms positively influence green purchase intentions.

\section{Relationship between Willingness to pay more and Green Purchase Intention}

Economic value is determined by measuring the maximum amount of willingness for a person to sacrifice to obtain goods and services (Hartono \& Harahap, 2007). How much a customer is prepared to pay extra for a product in order to reap the financial and emotional rewards of doing so" (Anderson, 1996). A desire to pay more for ecologically friendly/green items is also described in the relevant literature (Hsu et al., 2017; Kotler \& Zaltman, 1971; Laroche et al., 2001; Ling, 2013). It was found that willingness to pay more is positively associated with green purchase intention by ( $\mathrm{Ng}$ et al., 2018) in a study. There are many factors that contribute to the price of a green product being more expensive than the price of an otherwise comparable product, such as increased production and logistics costs associated with green products as well as the use of environmentally friendly technologies and eco- 
labels for products. And a global poll found that more than 55\% of customers are prepared to pay a premium to support firms devoted to environmentally friendly output, and $52 \%$ of global consumers had purchased at least one product or service from at least one ecoconscious company in the last six months (Nielsen, 2014). Therefore, following (Ng et al., 2018), this study hypothesized the following:

H7: Willingness to pay more positively influences the green purchase intention.

\section{Mediating Role of Willingness to pay more}

Given that this research hypothesized the influence of attitudes toward environmentally friendly products, environmental concern and subjective norms on willingness to pay, as well as the effect of consumers' willingness to pay more on green purchase intention, this study rationally anticipates that willingness to pay more will mediate the effect of attitudes toward eco-friendly product, subjective norms, and environmental concern on green purchase intention. According to TPB, intention is also supported by the theory (willingness to pay) should totally mediate the effects of predictor factors (i.e., attitudes toward eco-friendly product, social norms, and concern) on consumer purchase intention (I. J. O. b. Ajzen \& processes, 1991). As a result of this investigation, the following hypotheses are proposed:

$H 8 a$. WTP plays the role of mediator between the relationship of attitude toward green product and green purchase intention.

$H 8 b$. WTP plays the role of mediator between the relationship of environmental concern and green purchase intention.

$H 8 c$. WTP plays the role of mediator between the relationship of subjective norms and green purchase intention.

\section{Methodology \\ Participants and Sampling Design}

The Population of this study is who at the very least have a working knowledge of environmentally friendly products were classified by a study population. All those people who drive their own car and use gasoline collected data and educated farmers using pesticide for crops located in south Punjab. Hence in this research while following (Henry et al., 2003). Henry et al. (2003b, pp.31-40), 300-400 sample size is considered good enough to yield reasonable results. To test our hypotheses, the respondents were approached through selfadministered survey and questionnaires were distributed. Those who are aware of green products or have some understanding of them were selected for our study by use of a convenience sample technique. A final sample of 339 responses was collected through questionnaire and online survey technique s (i.e. using a link of an online Google form).

\section{Measurements}

Sections on customer demographics and questions on all possible constructs were included in a survey form to measure the green purchase intention. To measure their level of agreement or disagreement, participants filled out a five-point Likert scale ranging from 1 to 5 (Wang et al., 2014). The measurements used in this study are adapted and adopted from past research in this area. The scale of 20 items measuring the variables like as green purchase intention (4 items) adopted from (Bolton \& Drew, 1991). The attitude toward green product contains 4 items adopted from (McCarty \& Shrum, 1994). The environmental concern contains 2 items adopted from (W. Kilbourne \& Pickett, 2008), as used by (Paul et al., 2016) and 4 items adopted from (Abdul-Muhmin, 2007). The subjective norms contain 3 items adopted from (Arvola et al., 2008; A. Chen \& Peng, 2012; Dean et al., 2012; Sparks et al., 1997). willingness to pay more contains 3 items adopted from (Jang et al., 2011) and (Kang et al., 2012). 


\section{Results \\ Analytical procedures}

This data was analyzed through SPSS and Smart PLS, not frequently used in past studies. The data were analyzed using descriptive and inferential statistics. SPSS 21 was used for descriptive analysis which attempted to explain a thoroughness of profiling, demographics, etc. by summing up the figures and giving a variety of table formats and also by displaying how often different outcomes occurred (Agresti et al., 2009).

For inferential statistics, the conceptual model was put to the test using partial least squares structural equation modelling (PLS-SEM). PLS-SEM has been acknowledged by marketing researchers across a range of disciplines (Channa et al., 2020; Tariq et al., 2020). As a result, PLS-SEM was the most effective option for doing the analysis because it was designed to predict green buy intention (Memon et al., 2017; Hair et al., 2013). As a result, the Smart PLS 3 software has been employed in this investigation with a two-step approach (Hair et al., 2013;Ringle et al., 2012).

\section{Measurement Model Assessment}

Measurement model were evaluated using a criteria developed by Hair Jr et al. (2016) to evaluate the factor loadings, Cronbach's $a$, composite reliability (CR), and average variance extracted (AVE) in the measurement model. Detailed findings of the measurement model are shown in Table 1 and Figure 2. Given that reliability is a prerequisite, the reliability of the indicator is first verified such that the indications linked with the latent construct have much in common. Following examination of outer loadings for all latent variables 20. Meanwhile, 2 indicators (EC3_1, EC4_1) are found to have loadings between 0.4 to 0.7 . Therefore, for these two indicators a loading relevance test is done to determine if they are sustained in the model. As both indicators are deleted from the PLS model, the average variance extracted (AVE) and their respective latent constructs are increased. All other indicators are retained since they have 0.6 or greater outer loadings (Wong, 2016). Cronbach's $a$ and CR values were likewise higher than the recommended threshold of 0.70. (Bagozzi \& Yi, 1988; Hair Jr et al., 2016). Next, we tested the AVE to report convergent validity, as shown in Table 1, each of the latent variables had an AVE value higher than 0.50, indicating significance (Hair Jr et al., 2016). The Heterotrait-Monotrait ratio of correlation criteria was used to determine the discriminant validity. A look at the data in Table 2 reveals that each value falls below the 0.85 criterion set by (Henseler et al., 2016).

Table 1. Measurement model assessment

\begin{tabular}{lccc}
\hline Constructs & Cronbach's $a$ & CR & AVE \\
\hline Attitude toward green products & 0.831 & 0.887 & 0.664 \\
Green purchase intention & 0.87 & 0.912 & 0.721 \\
Environmental concern & 0.74 & 0.834 & 0.561 \\
Subjective norms & 0.811 & 0.887 & 0.724 \\
Willingness to pay more & 0.659 & 0.814 & 0.598 \\
\hline
\end{tabular}




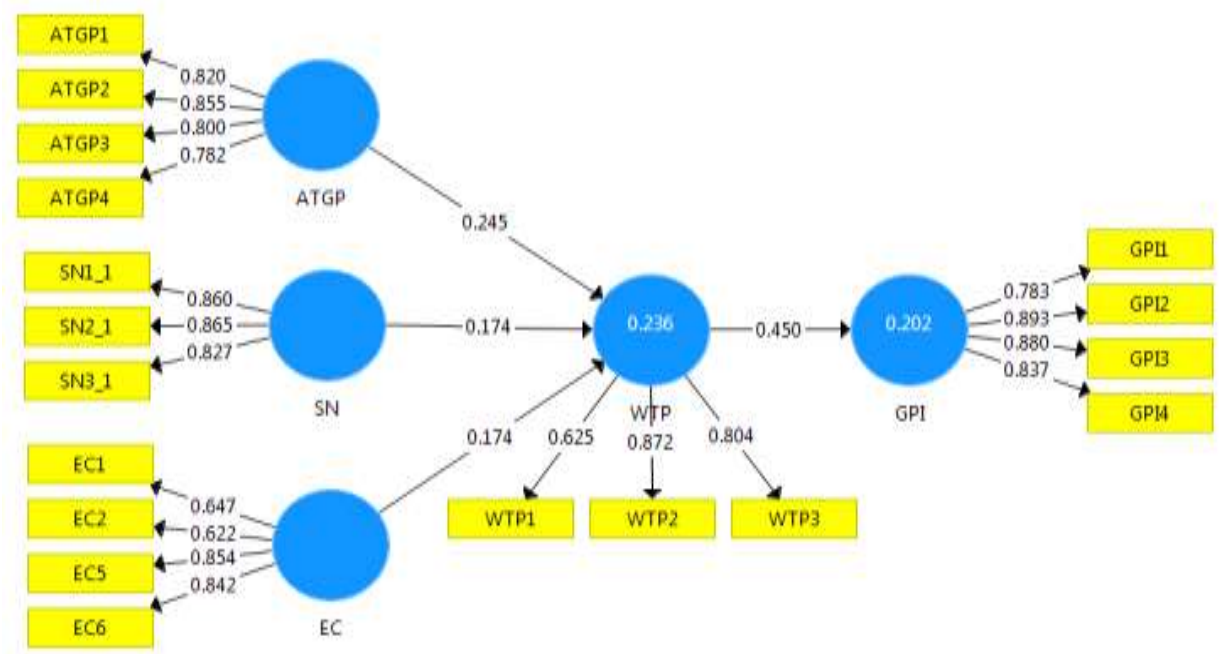

Figure 2. Measurement Model Assessment

Notes: ATGP=Attitude toward green products, $\mathrm{SN}=$ Subjective Norm, $\mathrm{EC}=$ Environmental concern, $\mathrm{WP}=$ Willingness to pay more, GPI=Green purchase intention, GOGP= Green oriented government policy

Table 2. Discriminant Validity Assessment

\begin{tabular}{llllll}
\hline Constructs & ATGP & EC & GPI & SN & WTP \\
\hline ATGP & & & & \\
EC & 0.628 & & & \\
GPI & 0.356 & 0.500 & & \\
SN & 0.731 & 0.483 & 0.221 & \\
WTP & 0.572 & 0.494 & 0.574 & 0.527 \\
\hline
\end{tabular}

\section{Assessment of Structural Model}

First of all, to determine multi-collinearity, the variance inflation factor (VIF) was used. All the VIF values within the acceptable limits of 5 given by (Hair Jr et al., 2016), in order to show that the exogenous variables do not have multi-collinearity (Table 3).

\section{Assessment of Path Coefficients}

With 5,000 sub-samples, the standard bootstrapping procedure was applied, using the onetailed test at 0.05 significance level and 304 cases to regulate the significance of path coefficients as suggested by (Hair et al., 2013; Hair Jr et al., 2016; Henseler et al., 2016).

Table 3 includes all of the structural model's statistics, including the mediating and moderating interactions. H1 hypothesized that attitude toward green product is positively related to willingness To Pay More. Results show that there is a positive correlation between attitude and wtp, hence supporting $\mathrm{H} 1(\mathrm{~b}=0.247, \mathrm{t}=3.05, \mathrm{p}<0.05) . \mathrm{H} 2$ : This hypothesis was also accepted on the basis of statistically acceptable figures. The results showed that there was a significant influence of environmental concern on willingness to pay more with a positive coefficient of $0.168, \mathrm{t}=2.938, \mathrm{p}<0.05$, thus the proposed hypothesis got accepted. Similarly, significant influence of subjective norms on willingness to pay more with a positive coefficient of $0.174, \mathrm{t}=2.657, \mathrm{p}<0.05$, supporting $\mathrm{H} 3$. The findings showed that there was no significant influence of attitude toward green products directly on green purchase intention with a value of $(b=0.067, t=0.845, \mathrm{p}>0.05)$ thus the proposed hypothesis 
was rejected $\mathrm{H} 4$. The findings indicated that there was a considerable impact of environmental concern on green purchase intention with a positive $(b=0.284, t=4.374, p<$ 0.05), therefore accepting the proposed hypothesis H5. H6: The findings showed that there was no significant influence of subjective norm directly on green purchase intention with a value of $(b=-0.093, t=1.304, p>0.05)$ thus the proposed hypothesis was rejected. Likewise, the results showed that there was a significant influence of willingness to pay more on green purchase intention with a positive coefficient $(b=0.356, t=4.883, p<0.05)$ therefore accepting the proposed hypothesis $\mathrm{H} 7$.

Apart from, exogenous variable's coefficient of determination $\left(\mathrm{R}^{2}\right)$, predictive relevance $\left(\mathrm{Q}^{2}\right)$ and effect size $\left(\mathrm{F}^{2}\right)$ were examined in this study (attitude toward green products, environmental concern, and subjective norms) on the endogenous variable (willingness to pay more, green purchase intention). The results (Table 3) suggest that R2 value for willingness to pay more is 0.232 which is moderate to explain variance in willingness to pay more by attitude, environmental concern, subjective norms and for green purchase intention is 0.284 which is substantial enough (Cohen, 1988) to explain variance in green purchase intention by attitude, environmental concern, subjective norms.

Subsequently, $\mathrm{Q}^{2}$ for willingness to pay more and green purchase intention suggests the predictive relevance of independent variables (attitude toward green products, environmental concern, subjective norms) for the dependent variable (willingness to pay more and green purchase intention). According to Henseler et al. (2009), $\mathrm{Q}^{2}$ in the research model should be larger than zero, Table 3 demonstrate that it is larger than $0(0.132,0.198)$, and hence supports the predictive relevance of the study model.

$\mathrm{R}^{2}$ endogenous variable values reflect the strength of the model. A variable in a structural model may be affected/influenced by a number of different variables. Deletion of an exogenous variable may affect the variable dependent. F-square is the variation in $\mathrm{R}$-square when an exogenous variable is excluded from the model. The resulting change in $\mathrm{R}^{2}$ achieved as such is used to estimate the effect size $\left(\mathrm{f}^{2}\right)$ computed using the formula below (Hair et al., 2013):

$\mathrm{f}^{2}=\left(\mathrm{R}^{2}\right.$ included $-\mathrm{R}^{2}$ excluded $) /\left(1-\mathrm{R}^{2}\right.$ included $)$

Cohen (1988) recommended the guidelines for assessing $\mathrm{f}^{2}$ values are: $0.02,0.15$, and 0.35, respectively, represent small, medium, and large effects (Hair et al., 2013).

Mediation analysis: A third construct intervenes when two connected constructs, there is said to exist a mediating effect (Hair et al., 2013). During this study Smart PLS was used to analyse the data. By following the guidelines provided by (Hair et al., 2017), the research examined the mediation effect.

Table 3. Structure Model Assessment

\begin{tabular}{lcccccccc}
\hline Paths & VIF & Beta & SD & $\boldsymbol{t}$ values & $\boldsymbol{P}$ values & $\boldsymbol{R}^{2}$ & $\mathbf{Q}^{2}$ & $\mathbf{F}^{2}$ \\
\hline H1: ATGP > WP & 1.798 & 0.247 & 0.081 & 3.05 & 0.002 & 0.232 & & 0.042 \\
H2: EC > WP & 1.326 & 0.168 & 0.057 & 2.938 & 0.003 & 0.232 & 0.132 & 0.026 \\
H3: SN > WP & 1.580 & 0.174 & 0.066 & 2.657 & 0.008 & 0.232 & 0.023 \\
H4: ATGP > GPI & - & 0.067 & 0.08 & 0.845 & 0.398 & 0.284 & 0.008 \\
H5: EC > GPI & - & 0.284 & 0.065 & 4.374 & 0.000 & 0.284 & 0.198 & 0.081 \\
H6: SN > GPI & - & -0.093 & 0.071 & 1.304 & 0.192 & 0.284 & & 0.004 \\
H7: WP > GPI & - & 0.356 & 0.073 & 4.883 & 0.000 & - & - & -
\end{tabular}

Note: $\mathrm{SD}=$ standard deviations 
Table 4. Mediation

\begin{tabular}{|c|c|c|c|c|c|c|c|}
\hline $\begin{array}{l}\text { Hyp. } \\
\text { No }\end{array}$ & \multicolumn{2}{|c|}{ Hypothesized Effect } & Beta & $\begin{array}{c}t \\
\text { Values }\end{array}$ & $P$ Values & VAF & Decision \\
\hline \multirow{4}{*}{ H8 a } & $\begin{array}{l}\text { Without } \\
\text { Mediator } \\
\text { Direct effect }\end{array}$ & ATGP -> GPI & 0.308 & 6.122 & 0.000 & & \multirow{4}{*}{$\begin{array}{l}\text { Full } \\
\text { Mediation }\end{array}$} \\
\hline & $\begin{array}{l}\text { With mediator } \\
\text { Direct effect }\end{array}$ & ATGP -> GPI & 0.067 & 0.845 & 0.398 & 56.7 & \\
\hline & Indirect effect & $\begin{array}{l}\text { ATGP -> WP } \\
->\text { GPI }\end{array}$ & 0.088 & 2.255 & 0.024 & & \\
\hline & Total effect & ATGP -> GPI & 0.155 & 1.725 & 0.085 & & \\
\hline \multirow{4}{*}{ H8 b } & $\begin{array}{l}\text { Without } \\
\text { Mediator } \\
\text { Direct effect }\end{array}$ & $\mathrm{EC}->\mathrm{GPI}$ & 0.409 & 8.743 & 0.000 & & \multirow{4}{*}{$\begin{array}{l}\text { Partial } \\
\text { Mediation }\end{array}$} \\
\hline & $\begin{array}{l}\text { With mediator } \\
\text { Direct effect }\end{array}$ & $\mathrm{EC}->\mathrm{GPI}$ & 0.284 & 4.374 & 0.000 & 17.4 & \\
\hline & Indirect effect & $\begin{array}{l}\text { EC -> WP -> } \\
\text { GPI }\end{array}$ & 0.060 & 2.378 & 0.017 & & \\
\hline & Total effect & $\mathrm{EC}->\mathrm{GPI}$ & 0.344 & 5.452 & 0.000 & & \\
\hline \multirow{4}{*}{ H8 c } & $\begin{array}{l}\text { Without } \\
\text { Mediator } \\
\text { Direct effect }\end{array}$ & $\mathrm{SN}$-> GPI & 0.202 & 4.532 & 0.000 & & \multirow[t]{4}{*}{$\begin{array}{l}\text { Full } \\
\text { Mediation }\end{array}$} \\
\hline & $\begin{array}{l}\text { With mediator } \\
\text { Direct effect }\end{array}$ & $\mathrm{SN}$-> GPI & -0.093 & 1.304 & 0.192 & -202.1 & \\
\hline & Indirect effect & $\begin{array}{l}\mathrm{SN}->\mathrm{WP} \rightarrow> \\
\text { GPI }\end{array}$ & 0.062 & 2.487 & 0.013 & & \\
\hline & Total effect & $\mathrm{SN}->\mathrm{GPI}$ & -0.031 & 0.401 & 0.688 & & \\
\hline
\end{tabular}

After establishing the significance of the indirect impact, the strength of the mediator may be determined using the total effect and Variance Accounted for (VAF). Bear in mind that total effect=direct effect + indirect effect according to (Hair et al., 2013).

For $\mathrm{H} 8 \mathrm{a}$, the total effect $=0.155$. Meanwhile, $\mathrm{VAF}=$ Indirect effect/Total effect. In H8a, $\mathrm{VAF}=0.088 / 0.155=56.7 \%$. Alternatively, for the hypothesis H8a, $56.7 \%$ of ATGP effect on GPI can be explained via the WTP mediator. For H8b, the total effect is 0.344 . Meanwhile $\mathrm{VAF}=0.060 / 0.344=17.4 \%$. For H8c, the total effect is -0.031 . Meanwhile VAF $=0.062 /-$ $0.031=-202.1 \%$.

\section{Discussion}

Predicting the impact of independent variables (i.e. attitude toward green product, subjective norms and environmental concern) directly and indirectly on consumers' GPI. This study's findings demonstrate that attitude toward green product, subjective norms, environmental concern have a significant positive impact on consumers' willingness to pay more for green 
products. Attitude toward green product, subjective norms have an insignificant impact on consumer's green purchase intention, but environmental concern has a significant positive impact on consumer's green purchase intention. The mediation impact of willingness to pay more was verified in the connection between behavioural variables (attitude toward green products, environmental concern, subjective norms) and green purchasing intention. Hence, this study supported H1, H2, H3, H5, H7,H8a, H8b, H8c but did not support H4, H6.

This study's findings demonstrate that the person is generally conformist, or the direction of the attitude of the people they consider important. Sometimes direct instruction can affect attitude formation. We can adopt a positive or a negative attitude to these green products on the basis of this information. This study shows that after being informed directly about green products, and eventually being willing to pay more for green products, individuals show positive attitudes. Environmental concern has a substantial effect on one's willingness to pay extra. Additionally, the findings indicate that buyers who were more concerned about the environment paid a premium for green products. Thus, this study explores how environmental concerns influence the willingness to pay more for green products. Numerous studies have established that $\mathrm{SN}$ has a considerable and beneficial effect on customer decisions (M.-F. Chen \& Tung, 2014; Cheng et al., 2006; Han \& Kim, 2010; Y. J. Kim et al., 2013). SN has a beneficial effect on the willingness to pay more (WPM). The sole aspect evaluated was subjective norms, which were predicted to influence WPM (Sinthusiri, 2016). This study reveals that the firms and other external variables have not managed to develop positive consumer attitudes to green while customers are ready to pay a premium for environmentally friendly items, they do not change their purchasing intentions to green ones. Green manufacturing needs to launch a green product feature campaign. Our economic and occupational circumstances also contribute to the development of attitudes. Our socioeconomic background has an effect on our present and future attitudes. Green products in a developing country are more expensive than non-green products and innovative products. Thus, this study discovered that an individual's attitude toward green products had no effect on their intention to purchase green products. Additionally, the findings indicate that environmental concern is a predictor of green purchase intentions. It is argued that a green purchasing recommendation might be delivered most successfully by increasing Pakistani consumers' environmental sensitivity. Various environmental campaigns, such as "Go Green", should be promoted by politicians, business organizations, or any other NGO organization, in order to enhance Pakistani consumer knowledge or environmental concern. Pakistani customers may therefore enhance their readiness to buy green products. Additionally, current study sheds light on the relevance and influence of EC on green purchasing intentions. Mass media like TV, radio, and social media have a massive effect on forming the attitudes and beliefs of people through their way of communication. New knowledge about something offers the basis for the development of new cognitive attitudes towards it. This study demonstrated that the press and electronic media in respect of green products do not create societal pressure. This is why subjective norms do not influence green buying intentions.

Our study, however, suggests that if consumers can receive environmentally friendly products, they are prepared to give extra money. In addition, people like to purchase things in an environmentally responsible manner from companies. The results contradict earlier studies which have shown that price is a hurdle to the use of green practices. The mediation impact of willingness to pay extra was verified in the connection between behavioural variables (attitude toward green products, environmental concern, subjective norm) and green purchasing intention (H8a, H8b, H8c). Additionally, this study indicates the considerable indirect influence of an individual's attitude toward environmentally friendly items, environmental concern, and subjective standards on their desire to purchase environmentally friendly products. 


\section{Implications \\ Theoretical Implication}

Prior studies examined extensively the variables of the intention to buy Green products for consumers. However, willingness to pay more towards green products have been disregarded especially in the framework of a developing economy. In addition, willingness to pay more was not addressed in earlier studies and is an essential factor influence the intention to adopt green products. The novelty of this study is of contributing three levels of theoretical. First, this study adds components of green purchase intention to previous studies, particularly in connection with environmentally friendly products i.e. high octane fuel (euro 5). Second is that the study had provided the empirical results of green purchase intention at a product category level. Third, the study will provide information on the consumer GPI decisionmaking process by adding a mediating variable willingness to pay more in Pakistan's petroleum. No-one in the oil industries had yet witnessed the influence of WTP as a mediating variable.

\section{Practical Implication}

- These analyses can ensure that businessmen establish strategic plans and advise the government on the design of policies. Consumers who are positive about Green products are more inclined to purchase these products. These product manufacturers may work with the government to create a good picture of the green products and encourage customers to build a positive green product approach.

- Subjective norms have a favorable effect on green purchases. Consumers are quickly influenced by "significant others." Some highly recognized people, such stars or celebrities, could be involved in organizing campaigns to underline the importance of business practitioners to increase their market share. Therefore, manufacturers need to give more information, expertise and experience on how simple access to green products is for the consumer and how the pricing variations between green and nongreen products should be explained, showing the production costs and value of green products. Moreover, the average score for products was rather low.

- Education on green products can boost consumer awareness with less intent to purchase. Producer groups should be focused on a number of consumer groups' tailored marketing. Therefore, in order to identify the main green customers, the green consumer markets should be separated.

\section{Limitations and Future Research}

Although many concepts are covered in research, there are still limitations which can help researchers to expand this study. First of all, this study is a cross-sectional study due to time constraint. Secondly, the data for this study was gathered just from some educated people. Along with those actual customers, those actually consumers of green products weren't reached out to. Thirdly, this research focuses on the intention, not the actual buying behavior, but the purchases of green products.

There are always gaps in studies, there are many constraints in our study, and some guidance is provided for additional research, which can be a chance for other researchers to conduct future studies. On the basis of this specific study, which they aim to carry out in the near future, there are recommendations for future research. This study focuses on providing the TPB constructs with an individual level study. The research has developed a unique TPB model to detect the aim of green purchasing.

In future studies, another specific green product might be explored, and consumer buying intentions could be compared between green products. In this research, more exogenous variables can be introduced, such as media exposure. This could give practitioners a clearer image for the implementation of methods. The fact that there is no particular definition of "green product" is another limitation of this research. And finally, as stated in limitations, our model includes only one mediator. However, others can expand this model of research and 
attempt different mediator or two or more mediator for the same study in order to enhance generalizability and to get better results.

\section{Conclusion}

The majority of customers contribute to environmental pollution, as there are several purchase habits that create environmental damage. This study tried to understand customers' purchase intentions and behavioral factors lead to their intent to use green products, which leads to green consumption. With this current study in mind, we evaluate and examine a real and genuine problem of the contemporary environment called green purchase intention, and this idea has to be taken into account in Pakistan's industry. The theory of planned behavior was utilized to better comprehend this idea in order to evaluate a person's attitude and intention towards green products. Therefore, to understand the attitudes of consumers and their intentions to use green products are considered important for industrial sector of Pakistan. Though a concern towards green products is growing rapidly among consumers are now give a rise to green products industry and also highlight the green products importance although the practical implications and different strategies are still not developed by different industries of Pakistan. Generally, the concept of green is still very new for the markets of Pakistan. Thus, the organizations must understand the behaviors of consumers and explore how their buying patterns towards green products are affected by the attitude of using green and intentions to use green products.

This study provides a prediction of the influence of TPB variables in green product buyers' GPIs (i.e. attitude, subjective norms, and environmental concern) on the GPI for green products. In addition, the mediating influence of willingness to pay more on the relationship between consumers' GPI and its determinants (attitude toward green products, subjective norms, and environmental concern) is also being investigated. This study indicated in particular that subjective norms and environmental concerns are positively and strongly associated with the intention to buy green products for consumers excluding green product attitudes. The findings support the mediation of willingness to pay more for the relationship between behavioral factors and consumer's GPI. This study also presents significant practical and theoretical implications for green industry to work towards preserving a good attitude to green products. In addition, it must be encouraged to embrace strong social values and the easy usage of green products. The prices must also be considered carefully to increase consumers' acceptance of green products. In conclusion, this study shows that customers who adopt a high positive attitude and are more likely to be inducted to buy green products, subjective norms and environmental concerns. Green manufacturers therefore have a chance to leverage on this important fact to safeguard the environment and to reduce greenhouse gas emissions through the promotion of green products.

\section{References}

Abdul-Muhmin. (2007). Explaining consumers' willingness to be environmentally friendly. International Journal of Consumer Studies, 31(3), 237-247.

Agresti, Finlay, \& Pearson Prentice Hall: Upper Saddle River. (2009). Logistic regression: Modeling categorical responses. 483-518.

Ajzen. (1985). From intentions to actions: A theory of planned behavior. In Action control (pp. 11-39): Springer.

Ajzen. (1991). The theory of planned behavior. Organizational behavior and human decision processes, 50(2), 179-211.

Ajzen, \& processes. (1991). The theory of planned behavior. 50(2), 179-211.

Ali, Ullah, Akbar, Akhtar, \& Zahid. (2019). Determinants of consumer intentions to purchase energy-saving household products in Pakistan. Sustainability, 11(5), 1462.

Anderson. (1996). Customer satisfaction and price tolerance. 7(3), 265-274.

Arvola, Vassallo, Dean, Lampila, Saba, Lähteenmäki, \& Shepherd. (2008). Predicting intentions to purchase organic food: The role of affective and moral attitudes in the Theory of Planned Behaviour. 50(2-3), 443-454. 
Bagozzi, \& Yi. (1988). On the evaluation of structural equation models. 16(1), 74-94.

Bashir, Bayat, Olutuase, \& Abdul Latiff. (2019). Factors affecting consumers' intention towards purchasing halal food in South Africa: a structural equation modelling. Journal of Food Products Marketing, 25(1), 26-48.

Bolton, \& Drew. (1991). A multistage model of customers' assessments of service quality and value. Journal of consumer research, 17(4), 375-384.

Bredahl. (2001). Determinants of consumer attitudes and purchase intentions with regard to genetically modified food-results of a cross-national survey. 24(1), 23-61.

Charter. (1992). Greener Marketing: Responsible business. In: Green Leaf Publishing, Sheffield.

Channa, N.A., Bhutto, M.H., Bhutto, M., Bhutto, N.A. and Tariq, B. (2020), "Capturing customer's store loyalty through relationship benefits: moderating effect of retail innovation", European Business Review.

Chen, \& Chai. (2010). Attitude towards the environment and green products: Consumers' perspective. Management science and engineering, 4(2), 27-39.

Chen, \& Peng. (2012). Green hotel knowledge and tourists' staying behavior. 39(4), 22112219.

Chen, \& preference. (2007). Consumer attitudes and purchase intentions in relation to organic foods in Taiwan: Moderating effects of food-related personality traits. 18(7), 10081021.

Chen, \& Tung. (2014). Developing an extended theory of planned behavior model to predict consumers' intention to visit green hotels. 36, 221-230.

Cheng, Lam, Hsu, \& Research. (2006). Negative word-of-mouth communication intention: An application of the theory of planned behavior. 30(1), 95-116.

Cline. (2007). Global warming and agriculture: End-of-century estimates by country: Peterson Institute.

Coddington. (1990). It's no fad: environmentalism is now a fact of corporate life. 15(7), 7.

Cohen. (1988). Statistical Power Analysis for the Behavioral Sciences. Hillsdle. In: Erlbaum. Conner, BE (1988). The Box in the Barn. Columbus: Highlights for ....

Dagher, \& Itani. (2014). Factors influencing green purchasing behaviour: Empirical evidence from the Lebanese consumers. 13(3), 188-195.

de Moura, Cunha, Castro-Cunha, \& Lima. (2012). A comparative evaluation of women's perceptions and importance of sustainability in fish consumption: An exploratory study among light consumers with different education levels.

Dean, Raats, \& Shepherd. (2012). The role of self-identity, past behavior, and their interaction in predicting intention to purchase fresh and processed organic food 1. 42(3), 669-688.

Do Paco, Raposo, \& Planning. (2009). "Green” segmentation: an application to the Portuguese consumer market.

Donaton, \& Fitch. (1992). Polls show ecological concern is strong. 63(24), 49-49.

Dunlap, \& Jones. (2002). Environmental concern: Conceptual and measurement issues. 3(6), $482-524$.

Eagly, \& Chaiken. (2007). The advantages of an inclusive definition of attitude. 25(5), 582602.

Fishbein, \& Ajzen. (1977). Belief, attitude, intention, and behavior: An introduction to theory and research.

Gooch, \& behavior. (1995). Environmental beliefs and attitudes in Sweden and the Baltic states. 27(4), 513-539.

Grunert. (1993). Everybody seems concerned about the environment: But is this concern reflected in (Danish) consumers' food choice?

Ha, \& Janda. (2012). Predicting consumer intentions to purchase energy-efficient products.

Hair, Hult, Ringle, \& Sarstedt. (2013). A primer on partial least squares structural equation modeling (PLS-SEM). Sage.

Hair, Hult, Ringle, \& Sarstedt. (2017). A Primer on Partial Least Squares Structural Equation Modeling (PLS-SEM) (English Edition) 2. Auflage, Kindle Ausgabe. 
Hair Jr, Hult, Ringle, \& Sarstedt. (2016). A primer on partial least squares structural equation modeling (PLS-SEM): Sage publications.

Han, Hsu, \& Lee. (2009). Empirical investigation of the roles of attitudes toward green behaviors, overall image, gender, and age in hotel customers' eco-friendly decisionmaking process. 28(4), 519-528.

Han, \& Kim. (2010). An investigation of green hotel customers' decision formation: Developing an extended model of the theory of planned behavior. 29(4), 659-668.

Hartono, \& Harahap. (2007). Willingness to Pay for Drinking Water and Sanitation Availability in Indonesia. Retrieved from

Henry, Lapenu, Zeller, \& Sharma. (2003). Microfinance poverty assessment tool: The World Bank.

Henseler, Hubona, Ray, \& systems. (2016). Using PLS path modeling in new technology research: updated guidelines.

Henseler, Ringle, \& Sinkovics. (2009). The use of partial least squares path modeling in international marketing. In New challenges to international marketing: Emerald Group Publishing Limited.

Hsu, Chang, Yansritakul, \& Services. (2017). Exploring purchase intention of green skincare products using the theory of planned behavior: Testing the moderating effects of country of origin and price sensitivity. 34, 145-152.

Hume, Strand, Fisher, Fitzgerald, \& Freeman. (1989). Consumers go green. 25(3), 3-5.

Jager. (2000). Modelling consumer behaviour: Universal Press The Netherlands.

Jaiswal, \& Kant. (2018). Green purchasing behaviour: A conceptual framework and empirical investigation of Indian consumers. Journal of retailing and consumer services, 41, 6069.

Jang, Kim, \& Bonn. (2011). Generation Y consumers' selection attributes and behavioral intentions concerning green restaurants. International journal of hospitality management, 30(4), 803-811.

Kahn, \& Management. (2007). Do greens drive Hummers or hybrids? Environmental ideology as a determinant of consumer choice. 54(2), 129-145.

Kalafatis, Pollard, East, \& Tsogas. (1999). Green marketing and Ajzen's theory of planned behaviour: a cross-market examination.

Kang, Stein, Heo, \& Lee. (2012). Consumers' willingness to pay for green initiatives of the hotel industry. International journal of hospitality management, 31(2), 564-572.

Kaufmann, Panni, \& Orphanidou. (2012). Factors affecting consumers' green purchasing behavior: An integrated conceptual framework. 14(31), 50-69.

Kilbourne, Dorsch, McDonagh, Urien, Prothero, Grünhagen, . . Bradshaw. (2009). The institutional foundations of materialism in western societies: A conceptualization and empirical test. 29(3), 259-278.

Kilbourne, \& Pickett. (2008). How materialism affects environmental beliefs, concern, and environmentally responsible behavior. 61(9), 885-893.

Kim, \& Choi. (2005). Antecedents of green purchase behavior: An examination of collectivism, environmental concern, and PCE.

Kim, \& Chung. (2011). Consumer purchase intention for organic personal care products.

Kim, Njite, \& Hancer. (2013). Anticipated emotion in consumers' intentions to select ecofriendly restaurants: Augmenting the theory of planned behavior. 34, 255-262.

Kinnear, Taylor, \& Ahmed. (1974). Ecologically concerned consumers: who are they? Ecologically concerned consumers can be identified. Journal of marketing, 38(2), 20 24.

Kotler, \& Zaltman. (1971). Social marketing: an approach to planned social change. 35(3), 312.

Lai, \& Cheng. (2016). Just-in-time logistics: Routledge.

Laroche, Bergeron, \& Barbaro-Forleo. (2001). Targeting consumers who are willing to pay more for environmentally friendly products. 
Laskova. (2007). Perceived consumer effectiveness and environmental concerns. Paper presented at the Proceedings of the 13th Asia Pacific Management Conference, Melbourne, Australia.

Lee. (2008). Opportunities for green marketing: young consumers. Marketing Intelligence \& Planning.

Lee, Hsu, Han, \& Kim. (2010). Understanding how consumers view green hotels: how a hotel's green image can influence behavioural intentions. 18(7), 901-914.

Ling. (2013). Consumers' purchase intention of green products: An investigation of the drivers and moderating variable. $1,14503-14509$.

Lopes, de Araújo Kalid, Rodríguez, Ávila Filho, \& Recycling. (2019). A new model for assessing industrial worker behavior regarding energy saving considering the theory of planned behavior, norm activation model and human reliability. 145, 268-278.

Mackay. (2008). Climate change 2007: impacts, adaptation and vulnerability. Contribution of Working Group II to the fourth assessment report of the Intergovernmental Panel on Climate Change. 37(6), 2407.

McCarty, \& Shrum. (1994). The recycling of solid wastes: Personal values, value orientations, and attitudes about recycling as antecedents of recycling behavior. Journal of business research, 30(1), 53-62.

Memon, M.A., Ting, H., Ramayah, T., Chuah, F. and Cheah, J.H. (2017), “A review of the methodological misconceptions and guidelines related to the application of structural equation modeling: a

Malaysian scenario", Journal of Applied Structural Equation Modeling, Vol. 1 No. 1, pp. 113.

Michaelidou, \& Hassan. (2010). Modeling the factors affecting rural consumers' purchase of organic and free-range produce: A case study of consumers' from the Island of Arran in Scotland, UK. 35(2), 130-139.

Mostafa. (2009). Shades of green: A psychographic segmentation of the green consumer in Kuwait using self-organizing maps. Expert Systems with Applications, 36(8), 1103011038.

Myburgh-Louw, \& O'Shaughnessy. (1993). Consumer perception of misleading and deceptive claims on the packaging of'green'fast moving consumer goods: University of Cambridge.

$\mathrm{Ng}$, Law, \& Zhang. (2018). Predicting purchase intention of electric vehicles in Hong Kong. 26(3), 272-280.

Nielsen. (2014). Doing well by doing good: the Nielsen company. Retrieved from https://www.nielsen.com/wp-content/uploads/sites/3/2019/04/global-corporate-socialresponsibility-report-june-2014.pdf

Paul, Modi, Patel, \& services. (2016). Predicting green product consumption using theory of planned behavior and reasoned action. 29, 123-134.

Pérez-Suárez, \& López-Menéndez. (2015). Growing green? Forecasting CO2 emissions with environmental Kuznets curves and logistic growth models. Environmental Science \& Policy, 54, 428-437.

Prakash, \& Pathak. (2017). Intention to buy eco-friendly packaged products among young consumers of India: A study on developing nation. 141, 385-393.

PSO. (2020). PSO Annual Report. Retrieved from file:///F:/Annual\%20reprts/pso\%202020.pdf

Qi, \& Ploeger. (2019). Explaining consumers' intentions towards purchasing green food in Qingdao, China: The amendment and extension of the theory of planned behavior. Appetite, 133, 414-422.

Ringle, C.M., Sarstedt, M. and Straub, D.W. (2012), "Editor's comments: a critical look at the use of PLSSEM", MIS Quarterly, pp. 3-14.

Roberts, \& Bacon. (1997). Exploring the subtle relationships between environmental concern and ecologically conscious consumer behavior. 40(1), 79-89. 
Sheppard, Hartwick, \& Warshaw. (1988). The theory of reasoned action: A meta-analysis of past research with recommendations for modifications and future research. 15(3), 325-343.

Sinthusiri. (2016). The effect of attitude toward green, subjective norms, perceived behavioral control, and perceived value on behavioral intention and willingness to pay more for Thai green hotels. Rajamangala University of Technology Thanyaburi. Business Administration ...,

Sparks, Guthrie, \& Shepherd. (1997). The dimensional structure of the perceived behavioral control construct 1. 27(5), 418-438.

Stern, Dietz, Guagnano, \& behavior. (1995). The new ecological paradigm in socialpsychological context. 27(6), 723-743.

Straughan, \& Roberts. (1999). Environmental segmentation alternatives: a look at green consumer behavior in the new millennium. Journal of consumer marketing.

Tan, Ooi, \& Goh. (2017). A moral extension of the theory of planned behavior to predict consumers' purchase intention for energy-efficient household appliances in Malaysia. 107, 459-471.

Tang, \& Medhekar. (2008). Drivers of green power electricity purchase. Paper presented at the Australian and New Zealand Marketing Academy Conference (2008).

Tariq, B., Najam, H., Maat, N.K.N. and Han, H. (2020), "Moderating effect of government regulations on the determinants of customer loyalty for cellular service providers in Pakistan", The Journal ofC ontemporary Issues in Business and Government, Vol. 26 No. 1, pp. 1-22.

TheWorldBank. (2019). Opportunities for a Clean and Green Pakistan A Country Environmental Analysis. Retrieved from file:///F:/thesis\%20articles/ariticle/pak\%20articles/Opportunities-for-a-Clean-andGreen-Pakistan-A-Country-Environmental-Analysis.pdf

Van Doorn, \& Verhoef. (2011). Willingness to pay for organic products: Differences between virtue and vice foods. 28(3), 167-180.

Vazifehdoust, Taleghani, Esmaeilpour, \& Nazari. (2013). Purchasing green to become greener: Factors influence consumers' green purchasing behavior. 3(9), 2489-2500.

Wang, Zhang, Li, \& Energy. (2014). Determinants of energy-saving behavioral intention among residents in Beijing: Extending the theory of planned behavior. 6(5), 053127.

Wong. (2016). Mediation analysis, categorical moderation analysis, and higher-order constructs modeling in Partial Least Squares Structural Equation Modeling (PLSSEM): A B2B Example using SmartPLS. 26(1), 1-22.

Yadav, \& Pathak. (2016). Young consumers' intention towards buying green products in a developing nation: Extending the theory of planned behavior. Journal of cleaner production, 135, 732-739.

Yadav, \& Pathak. (2016). Young consumers' intention towards buying green products in a developing nation: Extending the theory of planned behavior. 135, 732-739.

Zagata. (2012). Consumers' beliefs and behavioural intentions towards organic food. Evidence from the Czech Republic. 59(1), 81-89.

Zhao, Gao, Wu, Wang, \& Zhu. (2014). What affects green consumer behavior in China? A case study from Qingdao. 63, 143-151. 